Case Reports
in Dermatology
Case Rep Dermatol 2021;13:202-208

DOI: $10.1159 / 000513367$

Published online: April 7, 2021 (c) 2021 The Author(s)

Published by S. Karger AG, Basel www.karger.com/cde

\title{
Successful Treatment of Recurrent Dermatitis after Physalia physalis (Portuguese Man O' War) Envenomation with Extracorporeal Shock Wave Therapy
}

\author{
Leandro Dellanna $^{a} \quad$ Frank Hirche $^{\mathrm{b}} \quad$ Vasile Capra $^{\mathrm{c}}$ \\ aWitten/Herdecke University (UW/H), Witten, Germany; bermatology in Braunsfeld, \\ Cologne, Germany; 'Institute for Physical Therapy in Braunsfeld, Cologne, Germany
}

\section{Keywords}

Extracorporeal shock wave therapy · Contact dermatitis · Topical therapy · Exanthem - Sting reaction

\begin{abstract}
For more than 3 decades, extracorporeal shock wave therapy (ESWT) has been clinically implemented in urologic and orthopaedic indications. Here, we present the case of a patient with envenomation from a highly toxic jellyfish-like siphonophore (Physalia physalis) with a toxic contact dermatitis resulting in chronic eruptive skin lesions. The skin lesions on the dorsal right hand lasted more than 16 weeks and were refractive to local cortisone treatment. They finally healed after 8 applications of low-energy planar/defocused ESWT over 4 weeks. In detail, the clinical course, ESWT specifications and the possible mechanisms of ESWT in the light of the current literature are discussed. Our case indicates that ESWT is an underestimated, promising non-invasive, non-immunosuppressive treatment for chronic eruptive skin lesions after jellyfish or related toxin envenomations.




\section{Case Reports in Dermatology}

\begin{tabular}{l|l}
\hline Case Rep Dermatol 2021;13:202-208 \\
\hline DOI: 10.1159/000513367 & $\begin{array}{l}\text { (c) 2021 The Author(s). Published by S. Karger AG, Basel } \\
\text { www.karger.com/cde }\end{array}$ \\
\hline
\end{tabular}

Dellanna et al.: Successful Treatment of Recurrent Dermatitis after Physalia physalis (Portuguese Man O' War) Envenomation with ESWT

\section{Introduction}

Physalia physalis (Portuguese man o' war) accounts for extraordinarily painful stings and significant morbidity after envenomation and seems to be an increasingly frequent problem in the Mediterranean coastal regions [1] leading to a higher incidence of acute and chronic skin reactions. P. physalis (p.) is not a jellyfish but a siphonophore, an animal comprising countless individual polyps of 3 types working together. The 3 types are gastrozooid (feeding), dactylozooid (defensive) and gonozooid (reproductive). These polyps assemble to form the gross structures (e.g., bladder, tentacles, etc.). The name Portuguese man o' war derives from the upper polyp which is a gas-filled bladder at the water surface resembling an old warship at full sail and giving the organism the ability to sail with the wind for long distances [2]. Its original habitat is Australia and the Atlantic ocean, but increasingly it also occurs elsewhere [1]. Acute reactions and their treatment are extensively described, but sparse literature exists about prolonged cases and their treatment.

\section{Case Report}

Our patient is a 16-year-old boy who experienced a sting at the back of his right hand from P. physalis at the end of a dive close to the coast of a Spanish Mediterranean island. The animal was identified by one of the dive instructors and had also occurred before on the coast nearby, which was reported by a popular newspaper [3]. He had no prior medical history and no history of atopy or any known allergies. The family history is negative for dermatological conditions or allergies except for a mild seasonal allergic rhinitis of the boy's father. During the dive, the patient was protected on his head and body by a diving suit. The sting occurred after reaching the water surface while pulling off his equipment, having his hands unprotected. Immediately after the sting, the skin was carefully dried and a class II (referring to WHO classification) topical corticosteroid ointment was applied to the affected area. The hand was also cooled over $2 \mathrm{~h}$ with cooling packs, and contact with freshwater was avoided. $1.5 \mathrm{~h}$ after contact with $P$. physalis the affected hand was also immersed in vinegar and immobilised. Shown in Figure 1 is the affected hand $2 \mathrm{~h}$ after primary contact with $P$. physalis (on October 23, 2018, at 17:37). The affected area was reported to be initially very painful with a burning sensation, and over the first $12 \mathrm{~h}$, the right forearm and lower upper arm were also moderately sore. The skin lesion on the back of the right hand with pain and itching sensation continued to be present over the next 78 days after the event.

Topical class II corticoid treatment was used until the end of the first week and discontinued because of lack of improvement. During the following weeks, sharply demarcated erythematous infiltrated plaques on the back of the hand remained. Pain, especially when tensioning the skin by making a fist, and recurrent itching of the skin remained over the next 10 weeks. Due to the pain when stretching the skin, the movement of the hand was also impaired. At week 10, also superficial ulcerations developed.

Because there were no signs of spontaneous healing of the skin lesions, an attempt was made to treat the affected erythematous skin area with extracorporeal shock wave therapy (ESWT) starting on day 72 after the event as shown in Figure 2 (on January 8, 2019).

\section{Karger'=}




\section{Case Reports in Dermatology}

\begin{tabular}{l|l}
\hline Case Rep Dermatol 2021;13:202-208 \\
\hline DOI: 10.1159/000513367 & $\begin{array}{l}\text { c 2021 The Author(s). Published by S. Karger AG, Basel } \\
\text { www.karger.com/cde }\end{array}$ \\
\hline
\end{tabular}

Dellanna et al.: Successful Treatment of Recurrent Dermatitis after Physalia physalis (Portuguese Man O' War) Envenomation with ESWT

\section{Methods}

The English language public literature was searched using PubMed. ESWT treatment was performed in accordance with the manufacturer's operating instructions [4]. A planar/defocused shock wave (device: Storz Medical ESWT Duolith ${ }^{\circledR}$ SD1, T-Top version, C-Actor II handpiece, R-SW 1 V-Actor applicator) was used. Our treatment protocol consisted of 8 sessions with a focussed shock wave generated by a Duolith ${ }^{\circledR}$ SD1 machine plus a C-Actor ${ }^{\circledR}$ applicator, which defocuses the waves to adjust the penetration depth and energy applied. Treatment was administered twice per week. The focal depth of shock waves was $0-10 \mathrm{~mm}$ due to a 30$\mathrm{mm}$ standoff on the C-Actor applicator to optimise the penetration depth with a total energy applied for each impulse of $0.33 \mathrm{~mJ} / \mathrm{mm}^{2}$; wave frequency was $6 \mathrm{~Hz}$, and duration of each session was $15 \mathrm{~min}$ (2,000 pulses for a session per $133 \mathrm{impulses/min}$, total energy $21.58 \mathrm{~J}$ applied).

The first shock wave therapy took place on January 8, 2019 (day 72). After the second consultation on January 11, the patient reported that the chronic pain and itching of the skin was already reduced approximately by half. ESWT treatments as described above of approximately 15 min duration were performed 2 times a week (Tuesdays and Fridays) over 4 weeks. The treatment itself was painless and tolerated very well as no side effects were reported. As shown in Figure 3, after 4 weeks the erythematous plaques had considerably been reduced and there were also no more signs of ulcerations.

ESWT treatments were stopped at day 110. The described skin changes on the back of the right hand had completely disappeared without any signs of scarring. Even at a follow-up examination 1 year after the end of treatment and more than 18 months after the initial event, there were no signs of reoccurrence.

\section{Discussion}

Regarding ESWT evaluation in general, it has to be considered that the parameters of our treatment were chosen as described above following the recommendations by the manufacturer.

Unfortunately, no standardised commonly used parameters for the treatment of skin lesions with ESWT currently exist or can be found in the literature. It is important to stress that in this case, not radial shock waves generated by pressure waves were used but defocused/planar shock waves, which are electromagnetically generated [4].

On physical contact, $P$. physalis preys on its enemies by secreting toxins via intracellular organelles. The so-called nematocysts release the toxins through microscopic threads which pierce into the skin. The recommended first aid treatments, including acetic acid with hot water (cold water causes vasoconstriction, leading to a more severe and prolonged local reaction) and local lidocaine and systemic corticosteroids, aim at preventing the triggering of further nematocysts, which have not so far released their toxin $[5,6]$.

There are always acute reactions due to the toxins with erythema, local urticarial swelling, pain, burning and itching of the skin. These immediate skin changes usually last for hours, sometimes days, but are then self-limiting $[5,7]$.

Chronic persistent cutaneous reactions, as seen in our patient, occur far more rarely but have also been described in the literature [8]. The toxins are thought to be eliminated within several hours or days after the sting mostly through lymph vessels. In some cases, this can also lead to systemic reactions causing cardiac distress and difficulty in breathing. The extremely

\section{Karger'=}




\section{Case Reports in Dermatology}

Case Rep Dermatol 2021;13:202-208

DOI: $10.1159 / 000513367$

(c) 2021 The Author(s). Published by S. Karger AG, Basel www.karger.com/cde

Dellanna et al:: Successful Treatment of Recurrent Dermatitis after Physalia physalis (Portuguese Man O' War) Envenomation with ESWT

prolonged local reaction, as seen in our patient, cannot be explained in this way as the toxins would not remain in the affected skin area for such a long period.

One likely explanation for prolonged skin reactions, even lasting for a month, is that microscopic parts of the nematocyst threads remain in the connective tissue of the skin causing a local foreign body defence reaction. If the foreign material cannot be removed by macrophages and is not eliminated via the lymphatic system, the local immune reaction will persist. This would explain why in some cases described in the literature $[8,9]$ intralesional triamcinolone acetonide injections or the local application of immunosuppressive modulators, such as pimecrolimus and tacrolimus, could reduce the persistent skin changes only temporarily.

Repeated administration of ESWT may physically facilitate the removal of microscopic foreign material from the connective tissue of the skin and thereby eventually stop the chronic inflammatory reaction. Concerning a potential indication of ESWT for foreign body granuloma treatment, we would expect similarly positive treatment results as in our case depending on granuloma composition and microscopic structure. We recommend further studies with ESWT for foreign body granuloma.

There are certain limitations to this case report: This is a single patient who was well documented over a long period ( $>18$ months) without a control group. Therefore, a self-healing process cannot be excluded, although the time course and close therapy-associated response make a self-healing process unlikely. Another limiting factor is the absence of a histopathological specimen before and after treatment. If this had shown histopathological changes compatible with a foreign body defence reaction, this would have supported our explanation of the therapeutic mechanism. A skin biopsy was offered but not accepted by the patient because of the young age, no suspicion of malignancy and the delicate location of the affected skin. It would also have inevitably left a scar. So far, the described molecular effects of ESWT on the tissue level are a reduced inflammatory response, reduction of infiltrating leukocytes, reduction of fibroblast hyperplasia and neoangiogenesis, macrophage activity, lymphangiogenesis and NO production [10-12], so that ESWT is a beneficial candidate in the treatment of chronic scars [13]. ESWT has also been used in hypoxic non-healing chronic wounds [14].

To increase the reliability of ESWT of wounds in similar cases, one finger or part of the affected area could be treated separately from the others in order to compare healing effectiveness on an individual level. We recommend this asymmetrical treatment form for future studies as a non-invasive internal control for ESWT.

We describe here for the first time a case of ESWT in the treatment of a chronic inflammatory skin reaction.

ESWT has proven effects on adhesive musculoskeletal diseases, such as plantar fasciitis, and can detach adhesions [15]. Our case can be seen as an example in which ESWT resolves a chronic inflammatory skin reaction possibly by anti-adhesive and anti-inflammatory effects as well as promoting the removal of microscopic foreign material. In comparison to other treatments with immunosuppressive agents, ESWT is also free of side effects, well-tolerated and very cost-effective [11].

\section{Conclusion}

We suggest that ESWT may be a very effective physical treatment for chronic inflammatory skin reactions after contact with Portuguese man o' war and persisting forms of toxic

\section{Karger'"}




\section{Case Reports in Dermatology}

\begin{tabular}{l|l}
\hline DOI: $10.1159 / 000513367$ & $\begin{array}{l}\text { (c) } 2021 \text { The Author(s). Published by S. Karger AG, Basel } \\
\text { www.karger.com/cde }\end{array}$
\end{tabular}

Dellanna et al.: Successful Treatment of Recurrent Dermatitis after Physalia physalis (Portuguese Man O' War) Envenomation with ESWT

contact dermatitis. In further studies, standardised treatment protocols should be established for the use of ESWT in the treatment of these conditions.

\section{Statement of Ethics}

All procedures performed in studies involving human participants were in accordance with the ethical standards of the institutional and/or national research committee and with the 1964 Helsinki Declaration and its later amendments or comparable ethical standards.

Written informed consent for publication of this case report and any accompanying images was obtained from all individual participants included in the study.

This article does not contain any studies with animals performed by any of the authors.

\section{Conflict of Interest Statement}

The authors declare that they have no conflict of interest.

\section{Funding Sources}

The authors received no financial support for the research, authorship and publication of this article.

\section{Author Contributions}

Study conception and design: Leandro Dellanna. Acquisition of data: Leandro Dellanna. Analysis and interpretation of data: Leandro Dellanna/Frank Hirche. Drafting of manuscript: Leandro Dellanna. Critical revision: Frank Hirche/Vasile Capra.

\section{References}

1 Prieto L, Macías D, Peliz A, Ruiz J. Portuguese Man-of-War (Physalia physalis) in the Mediterranean: A permanent invasion or a casual appearance? Sci Rep. 2015 Jun;5(1):11545.

2 Haddad V Jr, Virga R, Bechara A, Silveira FL, Morandini AC. An outbreak of Portuguese man-of-war (Physalia physalis - Linnaeus, 1758) envenoming in Southeastern Brazil. Rev Soc Bras Med Trop. 2013 SepOct;46(5):641-4.

3 Spiegel Wissenschaft. Basel: „So gefährlich sind portugiesische Galleren“ [cited 2018 May 24]. Available from: https://www.spiegel.de/wissenschaft/natur/mallorca-so-gefaehrlich-sind-portugiesische-galeeren-a1209247.html

4 Duolith ${ }^{\circledR}$ SD1 application brochure ESWT, Storz Medical. Available from: www.storzmedical.com

5 Burnett JW, Calton GJ, Burnett HW, Mandojana RM. Local and systemic reactions from jellyfish stings. Clin Dermatol. 1987 Jul-Sep;5(3):14-28.

6 Ward NT, Darracq MA, Tomaszewski C, Clark RF. Evidence-based treatment of jellyfish stings in North America and Hawaii. Ann Emerg Med. 2012 Oct;60(4):399-414.

7 Burnett JW, Calton GJ. Jellyfish envenomation syndromes updated. Ann Emerg Med. 1987 Sep;16(9):1000-5.

8 Loredana Asztalos M, Rubin AI, Elenitsas R, Groft MacFarlane C, Castelo-Soccio L. Recurrent dermatitis and dermal hypersensitivity following a jellyfish sting: a case report and review of literature. Pediatr Dermatol. 2014 Mar-Apr;31(2):217-9.

\section{Karger'=}




\section{Case Reports in Dermatology}

\begin{tabular}{l|l}
\hline Case Rep Dermatol 2021;13:202-208 \\
\hline DOI: 10.1159/000513367 & $\begin{array}{l}\text { c 2021 The Author(s). Published by S. Karger AG, Basel } \\
\text { www.karger.com/cde }\end{array}$ \\
\hline
\end{tabular}

Dellanna et al.: Successful Treatment of Recurrent Dermatitis after Physalia physalis (Portuguese Man O' War) Envenomation with ESWT

9 Rallis E, Limas C. Recurrent dermatitis after solitary envenomation by jellyfish partially responded to tacrolimus ointment 0.1\%. J Eur Acad Dermatol Venereol. 2007 Oct;21(9):1287-8.

10 Sukubo NG, Tibalt E, Respizzi S, Locati M, d'Agostino MC. Effect of shock waves on macrophages: A possible role in tissue regeneration and remodeling. Int J Surg. 2015 Dec;24(Pt B):124-30.

11 Mittermayr R, Antonic V, Hartinger J, Kaufmann H, Redl H, Téot L, et al. Extracorporeal shock wave therapy (ESWT) for wound healing: technology, mechanisms, and clinical efficacy. Wound Repair Regen. 2012 JulAug;20(4):456-65.

12 Yan X, Zeng B, Chai Y, Luo C, Li X. Improvement of blood flow, expression of nitric oxide, and vascular endothelial growth factor by low-energy shockwave therapy in random-pattern skin flap model. Ann Plast Surg. 2008 Dec;61(6):646-53.

13 Saggini R, Saggini A, Spagnoli AM, Dodaj I, Cigna E, Maruccia M, et al. Extracorporeal Shock Wave Therapy: An Emerging Treatment Modality for Retracting Scars of the Hands. Ultrasound Med Biol. 2016 Jan;42(1):185-95.

14 Aschermann I, Noor S, Venturelli S, Sinnberg T, Mnich CD, Busch C. Extracorporeal Shock Waves Activate Migration, Proliferation and Inflammatory Pathways in Fibroblasts and Keratinocytes, and Improve Wound Healing in an Open-Label, Single-Arm Study in Patients with Therapy-Refractory Chronic Leg Ulcers. Cell Physiol Biochem. 2017;41(3):890-906.

15 Giordani F, Bernini A, Müller-Ehrenberg H, Stecco C, Masiero S. A global approach for plantar fasciitis with extracorporeal shockwaves treatment. Eur J Transl Myol. 2019 Sep;29(3):8372.

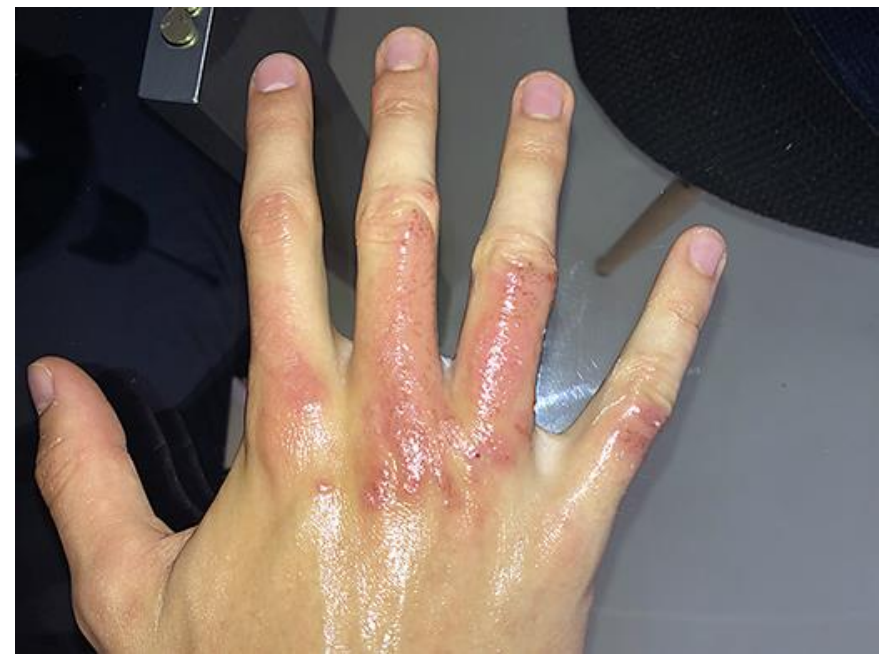

Fig. 1. Photograph of the toxic contact dermatitis due to the jellyfish sting on the hand of a 16-year-old boy. 


\section{Case Reports in Dermatology}

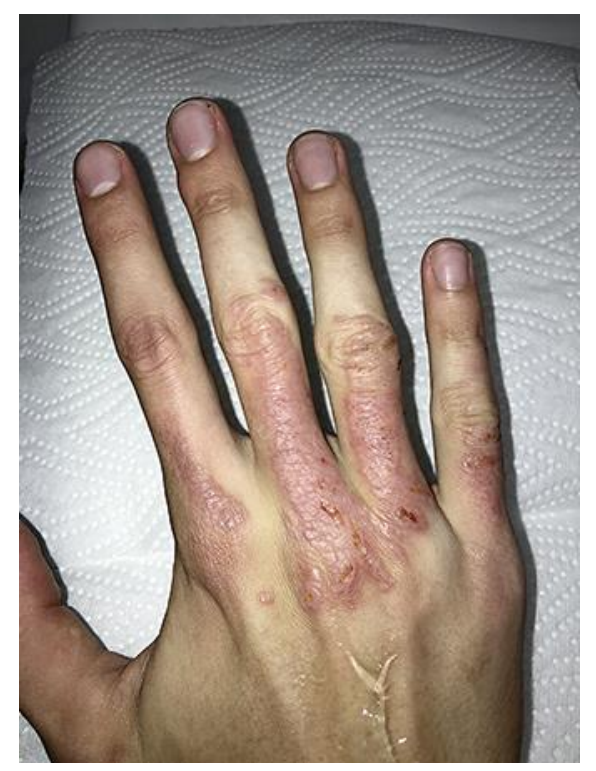

Fig. 2. Photograph shows the erythematous infiltrated plaques with ulceration prior to the first ESWT treatment on day 72. On the back of the hand, there is a small amount of ultrasound gel visible.

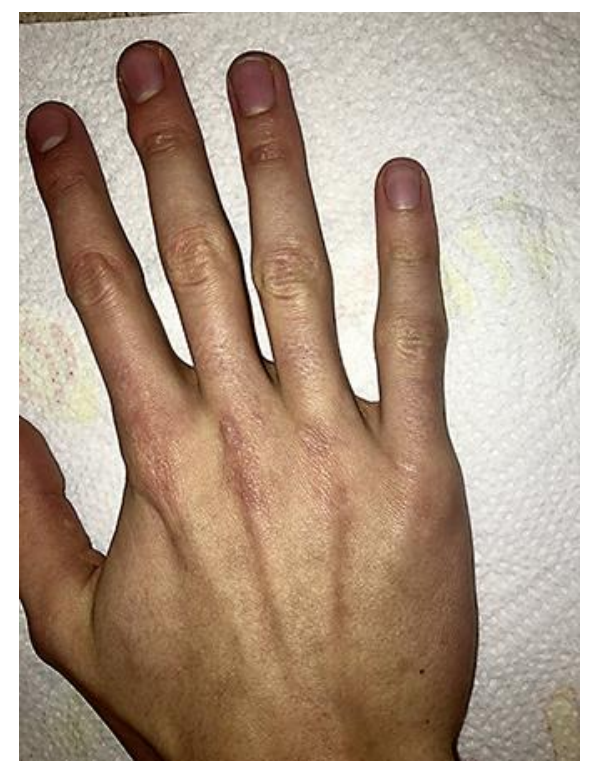

Fig. 3. Photograph shows completely healed skin area on day 110, after 4 weeks and 8 treatment sessions (each $15 \mathrm{~min}$ ).

\section{Karger'}

